What does the Matlab fertility experience really show?

$$
\text { John C. Caldwell and Pat Caldwell }
$$

Health Transition Working Paper No. 14, 1992 


\title{
What does the Matlab fertility experience really show?
}

\author{
John C. Caldwell and Pat Caldwell
}

The importance of the model provided by the Bangladesh fertility decline in general, and that in the Matlab District more specifically, can hardly be overstated. The national decline has occurred in one of the poorest countries in the world, without the governmental duress which has characterized some of the other Asian declines (J.C. Caldwell, 1992). The fertility transition in the ICDDR,B (International Centre for Diarrhoeal Disease Research, Bangladesh) experimental Treatment Area in Matlab District has been much steeper. Furthermore, it has been measured with precision and analysed in detail, so that it can be cited as an example showing what makes a family planning program work in difficult circumstances in a way that cannot be done for any other program. It is the obvious example to quote when discussing whether the Asian experience might be translated to Africa (cf. Caldwell, 1991). Yet what exactly does the Matlab experiment prove? The answer is not quite so straightforward as might be assumed, but it is of critical importance because the Matlab approach is expensive and labour-intensive even when diluted for national use. If all its ingredients were not equally necessary in Bangladesh, or - more importantly - if some are not essential in very different parts of the world, then family planning breakthroughs might prove possible at more affordable costs.

This article argues that the lessons of Matlab have been at least partly obscured or misinterpreted because of an excessive concentration on the supply or managerial side of that experience. This is, of course, partly a product of the highly organized, top-down nature of the ICDDR,B programs. This concentration has emphasized the key role of a high density of 'high quality', young, educated, female family planning workers who act specifically to teach about contraception and to provide the necessary reassurance about contraceptive side-effects and more generally to change society and especially women's confidence and decision-making powers. This interpretation is institutionally useful in that it maintains the staff's esprit de corps, justifies their employment, and also confirms the wisdom of the major decisions embedded in the history of the program. The interpretation is contained in a series of publications which, whether they do or do not embody the complete range of lessons which might be drawn from the Matlab experience, form the single most important corpus of texts on high-quality and effective family planning program management (e.g. Bhatia et al., 1980; Huber and Khan, 1979; Phillips et al., 1982, 1988, 1989a, 1989b, no date; Rahman, 1986; Rahman et al., 1978, 1979, 1980; Simmons, 1990; Simmons et al., 1988). Conversely there has been insufficient attention both in research and the literature on the demand side. We should know more about what the clients want, the extent to which the programs have been driven by client demand, and the user reaction to the availability of new types of contraception. The Matlab experience of two types of family planning provision in the second half of the 1970s has often been misunderstood so as to underestimate the importance of adding new contraceptive methods to the available cafeteria and accordingly to place a disproportionate emphasis on the type of service delivery, and especially on the characteristics of the service deliverers. Too little distinction has been made between the roles of service deliverers in providing explanation, moral support and new world views, and in making available otherwise unobtainable 
contraception. There has also been too little distinction made between what constitutes contraceptive availability in rural Bangladesh in contrast to other very different poor societies elsewhere in the world.

Let us first turn to Bangladesh nationally, partly to place Matlab in context, but partly also because the experience of the ICDDR, $B$ experimental areas ${ }^{1}$ has provided the whole country with evidence about how fertility in this society can be controlled and has almost certainly thereby accelerated the decline. The most recent World Development Report (World Bank, 1991) lists Bangladesh, equally with others, as the world's fifth poorest society, with in 1989 a per capita income of $\$ 180$, or just over half the regional level found in subSaharan Africa. Among the poorest 19 countries of the world it is one of only three outside that region. Among these 19 countries it had one of the highest fertility rates in 1965, but now, with a total fertility rate of 4.9 , it records easily the lowest because it is the only one where fertility transition is definitely under way. The conventional criterion which has been adopted for the onset of transition is a decline in fertility of ten per cent: by 1989 Bangladesh appeared to have achieved at least 30 per cent. This achievement occurred not only in spite of great poverty, but also in a country where 84 per cent of the population was Muslim with a tradition of female seclusion. Furthermore, 87 per cent lived in rural areas, for Bangladesh is among the ten countries in the world with the lowest level of urbanization. On the other hand, with 49 per cent of girls in elementary school in 1988, it did not do conspicuously badly by this measure, much better than Pakistan and a little below average for the world's 19 poorest countries. Yet it is salutary to note that it did better than the average for these countries 25 years ago, and even better than Pakistan does now, which may be one reason why the family planning program has achieved its present success, although the slow improvement since then may portend difficulties ahead. It also lies in the arc of countries from India through Southeast Asia to China and Korea where ruling elites have long claimed the right to provide moral leadership and now do so in the reproductive field (J.C. Caldwell, 1992). But the fact that Bangladesh is not an ancient state probably weakens such leadership potential. As part of Pakistan, Bangladesh came under the world's second oldest national family planning program (India being the oldest) from 1955, although it was not carried out with any vigour until the 1960s (Adil, 1966:125). The present intensive program in Bangladesh dates from 1976. During the time of these programs, Bangladesh's population has grown from 51 million or 933 persons per square mile at the 1961 census to 108 million or 1,936 persons per square mile at the 1991 census (Bangladesh Bureau of Statistics, 1991). This density is the highest national density in the world (i.e. excluding city states), about double that found in the Netherlands and Belgium.

The organization which is now ICDDR,B chose in 1963 an experimental field site for studying cholera in the Matlab District, a deltaic, riverine area 35 miles southeast of Dhaka, from which it is approached easily only by boat. A demographic surveillance system (DSS) was established to further the evaluation of cholera vaccines. By 1975 the surveillance system covered 260,000 persons living on 13 square miles of land, at a density of 2,000 persons per square mile, and in 233 villages which averaged around 1,100 persons each. In fact, the nucleated settlements tended to be smaller sub-villages. Within them, earth-

1 i.e. (1) Matlab field laboratory which occupies part of Matlab District to the southeast of Dhaka and which, with its Treatment and Comparison Areas, is the focus of most of this paper; and (2) the two Extension Project Areas in other directions from Dhaka, Sirajgonj and Abhoynagar. 
floored, mud-walled and thatched roofed one- or two-room houses were grouped into baris, often taking the form of squares surrounded usually on three sides by houses of related persons. The population was entirely rural, although one-fifth of the families were landless and many others had so little land that their chief support was from working as agricultural labourers or share croppers. With only 30 per cent of the population over five years of age literate, educational levels were below the national average but probably approximated the rural situation. In terms of religion the area also reflected the national situation with 85 per cent of the population Muslim and 14 per cent Hindu, most of the latter being fishermen. About ten per cent of the population derived income from outside the area, usually by their chief breadwinner working in jute mills or factories in other parts of the country. As late as 1982, in the villages studied by Rahman (1986), female seclusion still held sway in spite of two decades of ICDDR,B activities, and, apart from the Centre's own salaried employees, not a single woman worked outside the home.

In these rather forbidding circumstances, family planning projects were begun in the 1970s. In October 1974 the Johns Hopkins Fertility Research Project Clinic was established in Matlab Bazaar, the District Headquarters, and household work was begun in the nearest villages. One year later, in October 1975, the Contraceptive Distribution Project (CDP), the world's first fully measured saturation project in the provision of contraceptives to households, was begun with funding from USAID. Two years after that, in October 1975, the continuing Family Planning Health Services Project (FPHSP), later also called MCH-FP project, was commenced. It might be noted that from the commencement of the CDP in late 1975, the population was divided into two, the Treatment Area (TA) where experimental interventions were carried out, and the Comparison Area (CA), and these are the basic units for all later analysis. It might also be noted that the Comparison Area was closer to Matlab Bazaar than was the major segment of the Treatment Area, and closer to whatever quasiurban influences emanated from there, including the activities of the ICDDR,B diarrhoeal hospital. In addition, the Comparison Area included the villages first covered by the Johns Hopkins Project, and so initially recorded somewhat higher family planning levels than the Treatment Area. It was certainly affected to some extent by its contiguity with the Treatment Area, and has always been subject to the National Family Planning Program which has intensified and become more successful in recent years.

In 1975 the birth rates in Bangladesh as a whole and also in Matlab were around 49 per thousand but apparently already slowly falling (Shah and Cleland, 1988). In the whole country the first Bangladesh Fertility Survey (a component of the World Fertility Survey), carried out in 1975, showed 7.7 per cent of married women of reproductive age to be practising contraception, one-tenth of these marriages employing sterilization, one-half other modern methods, and the rest traditional methods. By 1988 the second Bangladesh Fertility Survey showed the national birth rate down to about 40 per thousand, driven by a current use of contraception which had climbed to 31 per cent (with sterilization almost onethird and other modern methods about two-fifths). By this time the Matlab Treatment Area birth rate had fallen about 40 per cent to near 30 per thousand, with current use of contraception around 60 per cent. Preliminary results from the 1991 Contraceptive Prevalence Survey indicate that the national contraceptive prevalence level has now reached 39 per cent. 
Three generalizations have been derived from the Matlab experience which have had an enormous impact on family planning conventional wisdom and practice around the world.

The first is that the contraceptive saturation approach had failed, as demonstrated by the experience of the CDP. In the words of Stinson et al. (1982:146), Thus, ubiquitous availability of contraception alone does not appear to be the solution to high birth rates in Bangladesh'. The experience of the CDP led to the new direction taken by the FPHSP, namely 'from a method-oriented to a client-oriented program' (Rahman et al., 1980:200).

The second is that, in areas where people are hesitant to employ contraception for one reason or another, the key to success is the warm supportive attitude of the family planning workers more than the type of contraception delivered. Furthermore, those most likely to succeed are said to be educated married young women who practise family planning and who come from well respected local families, the harbingers of the new society. Young women of this type drawn from the local 'establishment' are said to have succeeded in the FPHSP project whereas the uneducated, poor, old dais (traditional midwives) employed by CDP failed. Phillips and colleagues (1982:137-138), in a careful analysis of what had been learned, made their second summary point:

a user-oriented program with a wide choice of methods, skilled counselling, rigorous follow-up and treatment of side-effects, and ancillary health services, will be substantially more effective than one based on one or two methods distributed by unskilled workers.

Accordingly, in the national program the government 'replaced its part-time villagebased workers (dais) by a cadre of full-time, literate, female workers' (Rahman, 1986:14).

The third generalization is that the success of the program demonstrated that, after all, Bangladeshi women and their husbands were prepared to use contraception because they wanted to control family size. This assumption is made in the context of a vigorous debate about whether they were likely to want to do this at all. Cain (1977) had concluded from a study of a village in north-central Bangladesh that children, especially sons, provide parents with significant net economic returns through their labour, and subsequently (Cain, 1978:426) that 'the demand for labour in both family production and family maintenance is high, and the advantages of being able to draw on family labour are many'. In the latter publication, and later (Cain, 1981), in a comparison with India, he argued that in a rural environment where force could prevail, where there were periodic crises especially the traumatic life-cycle one following the death of the patriarch, and in the absence of developed capital markets, children, especially sons, were needed for long-term family security and for the protection of the family land. Khuda (1977), researching a village not far from Matlab, concluded that 'a large family, both boys and girls, is an asset on a traditional, pre-mechanized farm' (p.688), and that 'The high level of fertility is not primarily the result of the fact that family planning is not securing a rural toehold [but]... is ... in line with the views and desires of most of the people' (p.689). Nevertheless, 22 per cent of the males and 29 per cent of females in his study believed that a hypothetical friend who restricted family size to two children was wise and the same proportions failed to see anything good in a large family. Arthur and McNicoll (1978) expressed some surprise that there was in fact no poverty-driven fertility decline but concluded that the reason was that there were certainly eventual benefits in reproduction and that in the shorter run 'the high dependency within the population is scarcely noticeable within each family' (p.49), because the young couple at 
first lives with the husband's family, births are spaced, and children begin working at a young age. Robinson (1986), at a time when it was clear that fertility was falling, concluded that Bangladeshi peasants' time horizons were too short, because of the immediacy of crises, for long-term security guarantees to carry much weight with them. Shah and Cleland (1988:34) found from the evidence of fertility decline that 'the Matlab experience constitutes by far the most convincing evidence that there is a large latent demand for limiting fertility in countries such as Bangladesh'. They believed that this experience showed that neither high levels of child mortality nor low levels of female employment constituted an insurmountable barrier to fertility reduction, although there were more significant cultural and psychic barriers which exacted 'costs' from contracepting and which needed an appropriate service for their reduction.

We will, then, examine these three conclusions; (1) that the CDP project failed, while the FPHSP project succeeded, thus proving that it is not primarily the availability of contraception which leads to program success; (2) that the critical element in the success of the FPHSP project was the quality of the Female Village Workers whose household visits could legitimize the practice of contraception; and (3) that the FPHSP project proves the large latent demand for family limitation in the poorest societies, even those where child mortality is high and where women do not have other roles that compete with that of bearing and raising children, and that this latent demand can be actualized if the psychic and cultural costs can be reduced. First, it is necessary to examine some aspects of reproduction in the society in which this experiment took place, an examination made possible by the continuing research program itself.

We will need to deduce the reasons for behaviour from the demographic data, for curiously, in spite of the intensity of the research and the large field force, the people appear never to have been asked directly on any scale, or at all until recently, about the reasons for their reproductive, contracepting or lactating behaviour. These matters have now been touched upon in two focus group programs (Duza and Nag, 1988; Simmons et al., 1988; Simmons, 1990).

\section{Reproduction in the society where the experiment took place}

In 1974 women in Matlab were married early, on average at 16.9 years, although not as early as the Bangladesh Fertility Survey revealed for the whole country (Government of Bangladesh, 1978), to men eight years their senior. Female age at marriage was rising, and would climb two years by 1982 . Foster (1991) suggests that this was the result of a marriage squeeze, but the fact that rises of this order are found throughout Asia (Rele and Alam, 1988) suggests that it is part of a broader social change, of which female schooling is one element (Caldwell et al., 1983; B. Caldwell, 1992) and attitudes to family size could be another.

Marriage age determines the onset of reproduction, for all childbirth occurs within marriage. Even in rural Bangladesh some conceptions occur outside marriage, but Koenig et al. (1988) found that none in Matlab during the decade 1976-85 resulted in live births, either because the foetus was aborted or because the mother died in an attempt to procure an abortion or she died from violence related to the pregnancy. In fact, in spite of low levels of sex outside marriage, eight per cent of maternal mortality occurs to the non-married (three-quarters among the never-married and one-quarter among widows and divorcees). Of this mortality, seven-tenths arises from unsuccessful, clandestine and usually selfinduced abortion, while the balance is due to violence, either self-inflicted or from others. 
Even within marriage, the emphasis on female purity and seclusion presents dangers: in spite of five health facilities in the Matlab area 75 per cent of women dying in childbirth do not see a doctor before their death and 89 per cent do not get to modern health facilities(Fauveau et al., 1989:141). This strong association between female morality and the circumstances of reproduction does lend support to the view that it is an area of such potential trauma, where men and women find it hard to communicate and to understand each other, that legitimation might well be of central importance in the adoption of contraception. It also suggests that contraception, with the exception of clandestine abortion, is unlikely in the near future to find a market among the single, divorced or widowed.

Of central importance to an understanding of why contraception was accepted is the cycle of events surrounding conception and reproduction. Chen and colleagues (1974) carried out an intensive prospective study over two years, 1969 to 1971, of 209 married and presumably fecund women in two Matlab villages. Although the numbers were small, the results are illuminating and are unavailable from other sources. The intensity of the study, and the involvement of medical people, allowed the employment of bi-weekly interviews and monthly urine pregnancy tests. The latter revealed that miscarriages are three times as common as the DSS recorded and induced abortion probably seven times as frequent. The interviews showed that even then almost ten per cent of couples were practising some form of fertility control, well above the levels estimated from DSS, the discrepancy being largely explained by the fact that two-thirds of the users were employing withdrawal.

The study showed that the median duration of breastfeeding of surviving children was over 24 months, and that there was no real concept of a proper weaning age. 'Of 120 women who were breastfeeding at the beginning of the study, only three ended breastfeeding in the absence of pregnancy or infant deaths. These three women voluntarily ceased at 40 months' (Chen et al., 1974:289). One suspects that the reason, even among these three, was that so little milk was available that the effort of continuing was not worthwhile. These findings have been confirmed by other research. Huffman et al. (1980) reported that 75 per cent of 1500 rural Bangladeshi women in 1974 were, when the child survived, still breastfeeding 30 months after the birth. The main reasons for discontinuation were, during the first year, the death of the child, and in the second year the occurrence of another pregnancy, even though in the latter eventuality 50 per cent continued to breastfeed for six months and 19 per cent for nine months. Ford (1992) reports of a 1975-79 Matlab prospective study that the median age of weaning was 32 months.

An important question, in its own right and in terms of attitudes and aims likely to influence the success of the family planning program, is why children have been breastfed for so long. These questions have apparently not been explored with the Matlab families, but this has been done with rural south Indian families (Caldwell et al., 1988) and some of their explanations may be relevant to Bangladesh. One reason for lengthy breastfeeding was an unwillingness to forgo, in poverty-stricken circumstances where food was often scarce, what was regarded as a free good, part of nature's bounty, in the form of continuing maternal milk. Continuing feeding was regarded as traditional and natural; indeed nature would turn off the milk supply when that was appropriate. The likelihood of such behaviour remaining unchanged was reinforced in rural areas until the 1960 s because weaning decisions were primarily made by the feeding mother's mother-in-law. From that date younger couples began to assume decision-making in this area and weaning began to be 
uncoupled from the ensuing pregnancy. This was a reaction to social change, especially the education of women, but Hindu-dominated south India had greater pressures for such change than does Muslim-dominated Bangladesh. The Indian population believed, as did an earlier Europe (Flandrin, 1979), and as doubtless did pre-Muslim Bengal, that sexual activity harmed the quality of the milk and could endanger the child's survival. Islam, by teaching that sexual relations could be resumed 40 days after the birth, clearly taught that this was not so (and may now imply that contraception after that time is also not dangerous). As the duration of lactation in India began to shorten, which has happened most pronouncedly in the towns, women began to be threatened by more frequent pregnancies and regarded this as at best inconvenient, and at worst as a weakening and battering experience to be avoided if possible. This might be taken to imply that they earlier regarded uncurtailed breastfeeding as a method of maintaining long birth intervals, but the old women failed to corroborate this thesis, and clearly had believed when young that the birth intervals which existed then were natural rather than induced by lactation behaviour. Breastfeeding far into the next pregnancy may show a concern for the health of the suckling, at least if the child is receiving adequate supplementation. It also seems to show that the society had little belief that lactation during pregnancy might endanger the next child. Of course, given the evidence that the society placed a much higher priority on the survival of the first two sons and the first daughter than subsequent children (Muhuri and Preston, 1991), more concern with the safety of the present than the next child might be the logical response.

The next issue, then, is whether the situation described above is changing. The three specific Matlab studies reported span the period from 1969 to 1979. Admittedly, the evidence from India seems to be that the period of breastfeeding there was becoming shorter before this time, and Srinivasan et al. (1978) argue that, as a result of this and other effects of the move away from traditional behaviour patterns, the fall in fertility in Karnataka State between 1951 and 1975 was far less than the adoption of family planning would have indicated. In the few countries where successive WFS and DHS surveys can be compared, Asian periods of breastfeeding (measured by current status medians) seem to be falling, as do those of North Africa, in contrast to rises in Latin America and sub-Saharan Africa (Trussell et al., 1991). One reason is that not only are successive close pregnancies debilitating, but so also is an adult life made up of nothing but breastfeeding, pregnancy and birth. This is almost certainly true even in rural Bangladesh, where confinement to the home means that continued breastfeeding cannot be said to interfere with outside employment or other activities. It is relevant that in a society which was not seeking to reduce family size, namely the Yoruba of southwest Nigeria, there was a demand for contraception to allow the reduction of the periods of postpartum sexual abstinence and lactation (P. Caldwell and J.C. Caldwell, 1981; J.C. Caldwell and P. Caldwell, 1981) while retaining the traditionally required birth intervals. It is probably also relevant that the acceptance of family planning rose steeply during the 1980s. Nevertheless, any shortening of the duration of breast-feeding in rural Bangladesh has so far been very modest, for a lifetable approach to the estimation of the average period of breast-feeding of surviving children born in 1986-1989, as recorded by the 1989 Contraceptive Prevalence Survey, yielded a national figure of 30.6 months and a rural one of 30.9 months (Mitra et al., 1990:178). It is possible, of course, that lactational change was more rapid in the Matlab Treatment Area. 
Two questions remain. First, if the duration of breastfeeding declined at all during the 1980s and the concept of volitional weaning emerged, then what was the cause of this change? Secondly, how was this seen to endanger the birth interval if the concept of ordering the lactation period so as to ensure the right birth interval was not previously a cultural concept? The answer to the first question is hardly likely to be an economic one of the kind that postulates significant changes in the demands for women's time or new demands on women and the family as a result of the penetration of the market, for the evidence for rural Bangladesh is that these changes have not yet occurred. It is not, therefore, likely to rest on the development of a global economy, but it is likely to rest on the development of a global society. In those studies where we can hear people talking and catch glimpses of them (e.g. Duza and Nag, 1988; Rahman, 1986) it is clear that new ideas were coming in, especially through the media, and particularly by radio. Government programs might only be discussing whether children were being properly breastfed or properly weaned but they made behaviour in this area something for consideration or even discussion. Doubtless, in the Matlab Treatment Area the Female Village Workers accelerated this process. The second question is more difficult. The society may always have known, as researchers now do (Chen et al., 1974:292), that not only does breastfeeding delay the onset of the menses (known in traditional society because of early resumption of the menses after infant death), but that subsequent conception occurs less often to women who are still breastfeeding than those who are not. Alternatively, it may have been largely part of the new knowledge originating with the media and the health and family planning workers. One way or another, temporary methods of contraception were probably increasingly seen as a necessary substitute for prolonged breastfeeding.

\section{What did the Contraceptive Distribution Project prove about contraceptive availability?}

The CDP began in October 1975 with house-to-house delivery of orals (oral contraceptives) and condoms to a population of 125,000 living in 150 villages in the Treatment Area: this project, in fact, defined the Treatment Area and also the 135,000 population living in 84 villages in the Comparison Area although the two areas were at first given different titles. The most detailed published descriptions and analyses are by Huber and Khan (1979), Bhatia et al. (1980), Phillips et al. (1982) and Stinson et al. (1982). The most influential conclusions drawn were that the demographic impact was confined to the first year (Phillips et al., 1982: 132), that contraceptive availability alone was not the answer (Stinson et al., 1982:146) and that part of the failure probably arose from the use of the dais to supply services (Phillips et al., 1982:132).

There is a case for beginning our examination by looking at contraceptive prevalence rather than demographic impact, if only because the latter was so soon to be swallowed up in subsequent events as the FPHSP began in October 1977. It is not clear how often contraceptives were distributed, but in any case a six-month supply of orals was provided to acceptors. By the second round 89 per cent of women had been contacted and ' 69 per cent agreed to take a supply of pills' (Huber and Khan, 1979:248) and 35 per cent later said that they had at least tried them. Both the agreement and the fact that this level was far higher than the level of use recorded in any subsequent three-monthly survey shows there was a politeness response which may well have affected the survey response as well. Condom distribution began one year later. 
The surveys recorded that oral use rates among married women 15-44 years of age were 0.7 per cent in October 1975, peaked in February 1976 at 17.0 per cent and had fallen by November 1976 to 10.6 per cent. In the Comparison Area, affected by the earlier Johns Hopkins project, the levels were just over two per cent in late 1975 and late 1976. If the figures of the Treatment Area are to be believed, a multiplication of 24 -fold was no mean feat. But almost certainly there was a politeness response in both assenting that the pill had been used and also in trying its use. Pill use appears to have been down to about 3 per cent in late 1977 (Phillips et al., 1982:134). But what should be emphasized is that it did not subsequently climb much higher during the FPHSP; it was only about 4 per cent in late 1981. It would appear that the pill did not meet the needs of rural Bangladesh. There are probably two major reasons. The first is that space in the households is very limited and women have no place to hide away a supply of pills. Their very existence and noticeability might be taken to be indecent. The second is that in a busy life - even though largely confined to the house - they work such long hours, longer than their menfolk (Khuda, 1978; Caldwell et al., 1984), that remembering to take a pill daily is difficult. Condom use failed to rise much above 1 per cent during either the CDP (except for a probably spurious jump in the November 1976 survey just after distribution had begun), or the FPHSP, proof that the condom is no more acceptable in Matlab than in most of the rural Third World.

It is difficult to conclude that the CDP proved that accessibility to contraception was not the main path to fertility decline in rural Bangladesh. It and the FPHSP certainly proved that the pill and the condom alone were not going to effect the Bangladesh fertility transition. Support for the contention that this was an inadequate test of the importance of the availability of contraception can be found in the subsequent experience with injectables (DMPA or Depo Provera). From August 1976 a field assistant and a village worker (the old illiterate type) made monthly visits to six villages offering DMPA injections (Rahman et al., 1980). Almost from the time of first offer, around 15 per cent of eligible women were covered by this method and the level remained constant until the end of the CDP period. Furthermore, this plateau level was approximately the same as that achieved more generally throughout all the villages subsequently covered by FPHSP, and, in the first years of the latter project, accounting for half its contraceptive success.

\section{What did the Family Planning Health Services Project prove about contraceptive availability?}

From the beginning of the FPHSP in October 1977 contraceptive use rose steeply from around 10 per cent of married women of reproductive age until a plateau was reached in early 1979 at just over 30 per cent (Phillips et al., 1982:134). Thereafter, for several years contraceptive prevalence remained constant. The situation in the Treatment Area at the end of 1978 was that around 17 per cent of women were on DMPA, approximately the demand level suggested by the earlier CDP six-village trial; 4 per cent were on the pill, a level that CDP probably would have been able to maintain; 8 per cent were protected from conception by sterilization; 1 per cent were fitted with the IUD in the form of the Copper-T; and 4 per cent were using other means, mostly menstrual regulation and traditional methods but including some condoms.

On the face of it, these changes prove the success of a cafeteria offering of contraception in a situation where couples may only be tempted to take up family planning at all if there is a suitable method, and in the absence of the strong pressure to accept 
sterilization which has, for instance, often characterized the Indian program. Orals and condoms were at similar levels of use to those that the latter stages of the CDP indicated it could attract, while the use of injectables was also at the level of acceptance found in the six experimental villages. The increased contraceptive prevalence appears to have come about almost entirely from the availability of injectables throughout the whole Treatment Area, sterilization which became increasingly available from the beginning of the FPHSP, menstrual regulation which became available only from that date, and the Copper-T which was offered from early 1978. We really have no idea what would have been the position if these methods had all been made available earlier in a saturation project or in some other system of easy accessibility. The difficulty met in making comparisons is further compounded by the fact that the only fixed family planning facility during the CDP was the ICDDR, B hospital in Matlab Bazaar, but from the beginning of the FPHSP four additional subcentre clinics were established (Bhatia et al., 1980).

What is revealing about the FPHSP experience is the tremendous demand, especially among younger women, for temporary methods. This was an extremely important demonstration both for family planning program management and for an understanding of the Bangladeshi fertility transition. Sterilization made up only 22 per cent of all usage in late 1978 and 24 per cent in early 1981; even sterilization and the IUD together constituted only 27 and 34 per cent respectively at those two dates. This was unexpected in view of the Indian program's dominance by sterilization, and the justification frequently given for this that South Asian rural women do not need birth spacing because of their long periods of amenorrhoea and even longer periods of lactation, but what demand exists is for an eventual limit to be put on their fertility. Bangladesh was the ideal place for this contention to be tested, for it had the longest periods of lactation and amenorrhoea found by the WFS and DHS programs in the world.

The second point is that the demand can also be characterized as being for one-shot methods that do not require either coitally related or daily contraceptive action. By early 1981 pills and condoms made up only 14 per cent of all contraception and only 19 per cent even of temporary methods.

The discussion of the meaning of this surprising pattern is deferred until later.

\section{What did a comparison of CDP and FPHSP prove about service delivery?}

The conviction has grown with time that the major lesson to be derived from the comparison is that the FPHSP's success depended most on the relatively young and educated, supportive and contraception-experienced work force . It is, of course, an important conclusion for the organization itself in keeping morale at its highest, for the majority of its employees belong to the new FPHSP category. The real question for other poor parts of the world, where salaries and trainable persons are often scarce, is not whether it was advantageous, but whether that advantage was of such a margin that it can be regarded as necessary.

The decline in reported contraceptive use during CDP convinced everyone involved that the real issue was not availability but follow-up, reassurance and the reduction of the rate of drop-out. Phillips et al. (1982:137-138) concluded: 'Effects are likely to be temporary, however, unless distribution involves trained workers who systematically follow up users and attend to their needs. Since poverty and chronic ill health are widespread in rural Bangladesh, users are incapable of distinguishing side effects from other illnesses and cannot afford treatment for minor ailments', and again, 'a user-oriented program with a 
wide choice of methods, skilled counselling, rigorous follow-up and treatment of side effects, and ancillary health services will be substantially more effective than one based on one or two methods distributed by unskilled workers'. The latter statement is incontestable, but it does not distinguish between the relative contribution of method availability and service delivery.

Phillips et al. (1988:324) put the service delivery case at its strongest. In the CDP, complaints and rumors were widespread, and the capacity of the staff to respond to field problems was limited... A series of studies showed that women apparently wanted to practice, but feared contraception owing to side effects, and yet rarely turned to project staff for help.

Rahman et al., 1978 is cited, and the point is made that high discontinuation rates were due, in part, to low worker credibility.

Notions of relative social status, worker credibility, and inaccessibility prevented effective dialogue between CDP personnel and village women... Results suggested, in summary, support for the hypothesis that demand exists, but not for the CDP supply strategy: the staffing pattern, worker competence, supervisory system, clinical support system, and other features of CDP were inappropriate for the Bangladesh social system ... although the CDP failed to have major demographic effects, it demonstrated that 'supply' is not merely the provision of people, equipment, and things, but that the sociology of supply is as difficult to understand as the sociology of demand.

Huber and Khan (1979:247-248) reported that

The distribution project utilized the services of lady village workers (LVWs), or dais, and male field assistants (FAs) who had worked with CRL [Cholera Research Labouratory, earlier name of ICDDR,B] on field surveys and other health programs. LVWs were mostly illiterate village women... Although the word dai means indigenous birth attendant, in fact only 15 per cent of the dais were true traditional birth attendants. Most LVWs were elderly, many of them widows. Though the LVWs had the advantage of being able to move about the village freely, visiting other households (as most women observing the Muslim tradition of purdah or seclusion, did not), they had the disadvantage of being viewed with little respect because of their low social standing.

In fact, the LVWs were not without experience, for Rahman et al. (1980:192) reported: The LVWs are support workers, each responsible for 100-200 families in the neighborhood of her residence. For eight to ten years she has been making daily home visits to collect information on births, deaths, marriages and migrations and to detect diarrhea cases. She provides a simple remedy for mild diarrhea and refers severely affected patients to the CRL treatment center [i.e. the CRL diarrheal hospital in Matlab Bazaar].

These descriptions give a very definite impression, and have become part of global family planning lore. Therefore, a few clarifying points should be made. The real traditional birth attendants had not felt the role to be below them. There are, in fact, very few dais because most Matlab families have traditionally delivered the babies themselves. Certainly, the old women were apparently mostly illiterate (although they had played an important role in the demographic surveillance system's data collection over the previous 
decade). But this does not necessarily show that they were at the bottom of the social heap, for illiteracy among women of this age was well-nigh universal in rural Bangladesh at that date (Khuda, 1978:135). Similarly, because of the age gap between spouses and the high mortality level, nearly all women of this age were widowed. They may have come from the lowest social stratum, but no data on this point have ever been presented, and the fact that they were illiterate widows shows only that they were old. Certainly they did not observe purdah and moved freely around their village, but this merely indicates that they were postmenopausal. In addition, it should be remembered that this is not a caste Hindu society with absolute social rigidity and a submerged class at the bottom of the social pyramid. ICDDR,B staff who continue in employment from that period argue that the women could not have been from the elite families as such families at that time would not have allowed their older women to work outside the home. Admittedly, many were soon to allow their younger women to do so for the FPHSP, but this may merely show that they regarded education as transforming women in what they could do and should be permitted to do.

The FPHSP doubtless had good reason for wishing to create a social revolution by employing as Female Village Workers (FVWs) educated young women from reasonably well-off families - the three descriptive terms are almost synonyms - who could break purdah, provide role models, and communicate directly with the younger women of the household (they are older now, but they still provide role models). More specifically, they wanted educated young women who could react to complaints about side effects from contraception and provide explanations and reassurance. Nevertheless, it should not be concluded too readily that women of reproductive age - or their husbands - were likely to be much more attuned to educated young women than to postmenopausal old ones. Indeed, the whole region has traditionally regarded the latter group as being most qualified by dint of age, reproductive experience and postmenopausal status to be midwives, to deliver babies, to be a repository of knowledge about sexual relations and reproduction, and to be able to communicate to women of all ages this knowledge. In addition at Matlab they had a decade of experience in serving as the channels by which the male Field Assistants could ask questions of women about reproduction, children and deaths.

Three projects have asked questions about family planning workers with results which suggest that there may well be some substance in the issues raised above. Rahman (1986:77-79), reporting on an intensive study carried out in early 1982, found that client acceptance of contraception increased with the age of the FVWs, of whom the most successful were the one-seventh in his study area who were by that time over 30 years of age. Acceptance also improved with the FVW's fertility, being highest with those who had six or more living children, and with the age of the youngest child. Rahman concluded 'Most of the senior FVWs [i.e. those over 30 years of age] appear to have centrality in their families, either because of their age or because of the absence of a mother-in-law... they have relatively greater freedom, and definite authority, in taking decisions about their work' (p.79). Duza and Nag (1988), reporting on focus group discussions carried out in late 1986, found that even then one of the topics people wanted to talk about was the displacement of the CDP's LVWs by the FPHSP's FVWs. Both men and women said that, in the past, both they and the priests had felt that the young female FVWs were shameless in moving freely through the village, mixing with men, and following the 'doctors' i.e. the male Field Assistants who had matriculated from high school. 'Men used to say "Doctors have given 
jobs to chicks. Doctors have sacked the old midwives, have recruited chicks, move around with them'. Even nine years after this change, it was Duza and Nag's assessment, 'Even in the Comparison Area, and in spite of less regular contacts ... there appears to be a growing, albeit less than in the Treatment Area, social acceptance of the female family planning workers'. Their discussants said 'People don't criticize any more. They used to criticize in the past, now they are not in this business'. Simmons (1990:10-16) reported from a focusgroup study many comments on hostility to the FVWs in the crucial years of the late 1970s, the period for which the relative success of the FPHSP was being explained, commenting that these difficulties had been overcome by the mid-1980s.

The FVWs had to be married and mothers (Rahman:1986: 64ff.). They were selected only if they were residents of the locality in which they were to work, had a minimum of seven years schooling (i.e. at least two years in a high school which means they must have had to attend school during this period in the large market town which was the district headquarters), and if they had used contraception. Furthermore, they had to employ contraception during the first year of employment so as not to become pregnant. Preference was given to young women from families of high social status as measured by the amount of land the family owned, the occupation of the husband, and the representation of the relatives in the village leadership. It should be noted that these young women were in fact daughters-in-law who had married into families in these villages. It was the strength of the family into which they had married that gave them respect and freedom from molestation while they were carrying out such provocative activities as walking around the village discussing matters related to sexual activities. It is also likely that many had taken up contraception in order to get jobs in FPHSP. Rahman (1986) drawing on Rahman et al., 1979, maintained that the selection criteria were necessary because 'Experience with $\mathrm{CDP}$ suggests that a village woman is less likely to believe and adopt suggestions coming from a socially 'inferior' woman whom she perceives as being less knowledgeable than herself'. This may be so, but it is a remarkable picture of rural Bangladesh with hierarchical social leadership among women, an element of noblesse oblige, and absolutely no trace of class warfare. It also implies that knowledge is homogeneous and that there are no repositories within the society of respected specialized reproductive knowledge.

The program was shaken by the high discontinuation rate of the CDP (although much of this may have been more apparent than real). They believed that educated girls were needed who could be taught about contraceptive side-effects so that they in turn could teach this to the village women and provide reassurance. There is almost certainly something in this argument, for it is clear that the FVWs became ever more knowledgeable, self-assured and professional. Yet when Rahman (1986:78), in his 1982 field study, examined the acceptance level achieved by 77 FVWs, all admittedly with six or more years of schooling, the differentials in achievement by education were not great and the most educated performed worst.

With such heavy dependence on DMPA with its recognized side-effects, reassurance may be valuable. A study of all women who had first accepted these injections in July and August 1988 (Stewart et al., 1991) showed on subsequent interviewing that 93 per cent had experienced menstrual change (almost two-thirds amenorrhoea and one-third heavy bleeding), but only 69 per cent regarded themselves as having suffered from side effects. The impact of these side effects should not be underestimated: 56 per cent of all acceptors could not carry out religious rituals as before, 43 per cent had problems with housework and 
35 per cent with sexual relations. In-depth interviews showed that excess bleeding was much more distressing than amenorrhoea (Stewart et al., 1991:13). Of those with side effects, 42 per cent received some kind of treatment from the ICDDR,B system, most presumably as a result of consultation with the FVWs. What is surprising - and it is by no means clear whether it was the result of treatment and reassurance or just different personalities, degrees of self-direction and perceived need to avoid pregnancy - is that experiencing side effects was not a powerful determinant of continuing DMPA use: 32 per cent of those with such problems continued, while 39 per cent of those with no problems did so. It is also possible that in each case the major reason for discontinuation may have been the achievement of an acceptable birth interval.

It is known that contraceptive prevalence increased from 6 to 36 per cent (before dropping back to 32 per cent) in the first 15 months of FPHSP (Phillips et al., 1988:316) and that about 97 per cent of this increase can be ascribed to methods not available in CDP. Phillips et al. describe this as being due to 'the introduction of project services', but it is unclear whether they are placing most emphasis on the variety of methods which became available or on the new work force. They seem to be identifying the latter when they note that 'any interruption in the intensity or quality of contraceptive care was associated with pronounced disjunctures in the discontinuation rate and turbulent use dynamics', but their major example is given as a period when care was distracted by vaccines trials, which also happened to coincide with a DMPA shortage in Bangladesh.

It seems unlikely that the replacement of LVWs by FVWs was the main engine of such spectacular change over such a short time, and much more likely that the main explanation was the new availability of DMPA, sterilization and IUDs. It is possible, but will never now be proved, that the FVWs 'sold' these services better than the LVWs would have done, although the earlier success of the LVWs with DMPA in the six trial villages must leave an element of doubt even here.

Once this latent demand was satisfied, the FVWs may well have been responsible for maintaining a plateau of use over the next three and a half years in contrast to the apparent rapid decline in CDP rates (but here, again, much depends on how we evaluate the politeness effect in this program and also the new methods available to the FPHSP). From 1982 contraceptive prevalence began a persistent rise from just above 30 per cent of potential users to 50 per cent and beyond. It is unlikely that the FVWs had suddenly become more efficient than during the first four years of the new project. It seems probable that we are witnessing the impact of socio-economic change.

Two questions therefore arise. Why was there at the end of the 1970s a latent demand for contraception by one-third of married couples? What has driven the rise in demand since 1982?

\section{The latent demand for temporary methods of contraception in the late 1970s.}

No one in the debates of the 1970s as to whether large families were advantageous or disadvantageous implied that most of the latent demand for contraception was for birthspacing. Yet it is difficult to interpret the Matlab family planning acceptance figures in any other way. Once the full range of methods was available, only 23 per cent of acceptors chose sterilization and no more than 34 per cent sterilization and the IUD combined. Almost twothirds chose temporary methods, almost three-fifths of these opting for DMPA alone. Of 
the latter - and this may be true of all temporary methods - 62 per cent were under 27 years of age and 55 per cent had only one or two children, but none had no children (Stewart et al., 1991). It was the method chosen by almost half the women who wanted more children, but also by almost one-third who did not.

Why do these women want to space? This would appear to be the single most important question in understanding Matlab family planning, but it does not appear to have been asked. The failure to enquire may be explained by the fact that family planning programs assume that couples accepting contraception wish to limit family size. In the analysis of an individual case by Simmons et al. (1988:31, Case One), the husband is reported to have said that he wanted his wife to take the pill because 'I do not want another baby soon. She is only one year old'. The analysts concluded: 'In this case, both husband and wife clearly want to limit their family size'. By the standards of non-contracepting and non-abstaining societies, the existing intervals, with a median of 34 months (Chen et al., 1974:294) were not short. There is, however, a distribution around the mean which puts some women at greater risk and makes an even larger proportion apprehensive that this might happen: 21 per cent of all women, and 23 per cent of those under 30 years of age, had a birth interval of 24 months or less. There may also be some feeling that the lactation period is shortening, and with it the interbirth interval, even though these changes are probably rather modest as yet.

The major reason may be the desire to regain their strength fully. In those parts of West Africa where postpartum sexual abstinence is of longer duration than lactation, the reason given is that women need time to recover from the debilitating effect not only of pregnancy but also of breastfeeding (Caldwell and Caldwell, 1977:198). It may be possible that the Matlab women are also moving toward achieving this by weaning before the next pregnancy and continuing to use DMPA or some other temporary method for a period after weaning.

Another important reason may be the protection of either the present suckling or the next child. Certainly demographers have produced analyses showing that Bangladeshi children born close together have higher mortality than those born further apart, although it is also now clear that some of the effect arises from prematurity in the case of some of the second children, which results in both shorter birth intervals and higher mortality due to prematurity (Koenig et al., 1990; Mostafa et al., 1991; Miller et al., 1991). Apart from prematurity, the causes are probably early weaning in the case of the older child and maternal depletion in the case of the younger one. Early weaning in rural Bangladesh is associated with higher mortality, probably because the food and drink the children subsequently get may be contaminated in contrast to mother's milk (Shahidullah, 1991) and possibly because they no longer receive the protective antibodies in the latter. Mothers have probably long had a belief that these dangers to the children were associated with shorter birth intervals. One might ask, then, why do they endanger the second child by breastfeeding far into its gestation period? The answer may be that there is every reason for concentrating on the living child who has probably already survived the perils associated with infancy. This may be especially so if the living child is a son, but there are no published data on the sex of the breastfed child by the duration of breastfeeding into the next pregnancy. The hypothesis that priority is given to protecting the existing child is weakened by the fact that children of up to three years of age, who must be regarded as relatively safe, are still fed far into the next pregnancy. It may rather be a question of not forgoing a free 
good, or it may just be that the society has traditionally not regarded breastfeeding during pregnancy as threatening the future child's life.

The fact that DMPA and other temporary methods can be used on this scale during breastfeeding shows that there is no apprehension in the society of sexual activity injuring the milk, or indeed of DMPA or heavy menstrual bleeding resulting from it, doing so. The Muslim injunction to abstain from sex for 40 days after a birth presumably is taken to be a guarantee that there is no problem thereafter and perhaps, by implication now, that contraception is also not disfavoured after that time.

Contraception for spacing may well have a stronger effect, albeit unintended, than contraception for termination, in reducing the district's fertility levels. Such contraception will not only hold the birth interval constant by nullifying tendencies, driven by such forces as earlier weaning or better maternal feeding and health, for it to shorten, but will lengthen it by eliminating those shorter-than-average intervals which have always capriciously occurred. Indeed, if women are reluctant to conceive again at the traditional average time in order to protect their children, to augment their strength or to allow themselves more time for other activities, then temporary contraception may well lengthen the intervals, and this in turn will tend to reduce the number of births they can fit into their reproductive span. This is especially the case where there is a concept of sex being inappropriate once women reach a certain age or their oldest child reaches puberty or the women become grandmothers. That the latter at least is the case in Bangladesh has been shown from the data of the 1975 Bangladesh Fertility Survey (Tan, 1983). In addition, Rahman (1986:147) has confirmed that there is a more general embarrassment felt by older women who conceive. At the same time, the rise in the age of marriage is shortening the span of time available for reproduction.

\section{The demand to control family size or to terminate reproduction}

Controlling the ultimate family size and terminating fertility are two different aims, but both have the potential for reducing fertility. Throughout much of South Asia and in other parts of the world there is a belief that women should not have sexual relations when they have children who have reached puberty or when they are no longer young (cf. Caldwell et al., 1987:14-15), or have become grandmothers. If grandmothers do become pregnant, there can be a clash between their maternal and grandmaternal roles. Rahman (1986:147) believed that one reason for older Matlab women accepting family planning was the embarrassment of having children at an older age'. This was probably one of the reasons that by early 1979 almost 20 per cent of all contracepting women and 9 per cent of all women of reproductive age had sought sterilization, quite large proportions in view of the age structure of the population with its heavy concentration among the younger age groups.

Nevertheless, the desire to limit family size was probably more important. Shah and Cleland (1988, drawing partly on Cleland and Mauldin, 1987) argue that Bangladeshis have a desire for a family of only moderate size, that this desired size is, for instance, lower than that found in Pakistan, that the desired size has declined in recent years, and that real desires are reflected in the responses to survey questions on desired family size and whether more children are wanted. The average desired family size reported by the 1976 Bangladesh Fertility Survey (BFS) was 4.1, which, if it meant children surviving to their parents' old age, was, given the mortality level at the time, compatible with the existing fertility level. But younger women in the early stages of reproduction wanted a slightly smaller family size and those cohorts had not changed their minds when recorded 13 years 
later by the 1989 BFS. The latter survey recorded lower figures still among the new generation of young women so that the average desired family size was around three. According to the 1983 Contraceptive Prevalence Survey and the 1989 BFS the proportion of women with three surviving children who wanted no more children rose between those dates from 63 to 72 per cent. This is compatible with the demonstration by Muhuri and Preston (1991) from Matlab data that the first two sons and the first daughter in the family experience substantially lower mortality, presumably because this is the really needed core of the family toward whom scarce resources should be allocated to secure their survival. Two questions must be addressed: why are no more children than this desired, and why did the number desired fall during the 1980s - or alternatively what strengthened the conviction that family building could and should be constrained?

The moderate family size may partly rest on lack of resources, especially on Bangladesh's alluvial plains where the size of land holdings is limited, and consequently there is a ceiling on food production and on the labour that can be usefully employed. This would be in keeping with the Freedman and Freedman (1986) hypothesis of a povertydriven fertility decline. It is likely that a limit on available food, and on the number of hands needed to bring production to a maximum, is a factor in desiring only moderate fertility. Another factor may be an increase in the significance and real cost of dowries for daughters' weddings (P. Caldwell, 1990).

Yet Duza and Nag (1988) found in their 1986 focus group sessions, consisting of 56 meetings in 23 villages, that the desire to limit family size was essentially aspiration-driven, a reaction to the new society and economy and to the opportunities they offer. Their findings were, in fact, similar to those reached by Caldwell et al. (1982) in a study of a poor, rural area of south India. Schooling now provides an opportunity for children to leave farming and get non-agricultural employment in the expanding non-rural economy. Parents doubtless are over-optimistic about their children's chances of succeeding at school or of subsequently obtaining as good a job as they envisage. Nevertheless, they are right in their conclusion that the children have some chance of successfully climbing this ladder, and, if they do so, will earn money - in contrast to subsistence food production - and will continue to earn it through famine and flood disaster, thus raising their own standard of living and also being able to help their parents and siblings, and mitigate their risks. This is all-important in a very poor society where risk-reduction is central to personal planning and where there are few avenues of investment for doing this. It used to be done by maximizing the number of children. It might still be done by maximizing the number of educated children, but educating children is costly because the process inevitably incurs more expenditure and reduces children's labour inputs. If children are to be successfully educated, then it is usually necessary to concentrate on a limited number of them. This investment in children is, in poor societies, possible in a way that other investments are not, because it does not mean accumulating a proportion of income as savings while the family has insufficient food, clothing or shelter (Caldwell, 1981). One might also argue that families needed fewer births as mortality declined, but that decline has been very moderate, even in Matlab, and was not a significant theme in the Duza and Nag focus group discussions. Not all reactions to family size change are similar. Some parents who have controlled family size do report consequent problems with the size of the family work force, especially at times of peak labour demand (P. Cald well, 1990). 
These changes have developed slowly and are continuing to do so. They cannot, alone, explain the rise in Matlab contraceptive use since 1982 or the continued national decline in desired family size. The only sufficient explanation is the legitimation of the concept of the small family and of contraceptive use and the greater diffusion of the idea that there may prove to be economic advantage in controlling family size. In Matlab the FVWs have certainly played a role in this spread of ideas and in their legitimation, although there is some puzzle as to why there was no forward movement in the years 1979-81. Even in Matlab, national legitimation, especially as it was conveyed by radio, was also important, as the Duza and Nag reports show: People want two sons and one daughter. On radio they say two. We want one additional son because if one dies, then who will look after my property?'. But another said 'When radio said, people were not so convinced; when - came door to door and explained everything, then only people took it. Nobody took it just on hearing the radio'.

Nevertheless, the fact that it was on the radio as well almost certainly helped. In an arc from India through Southeast Asia to China and Korea, governments have given a moral leadership in the move toward family planning, and have been a powerful instrument in securing fertility declines at per capita income levels achieved nowhere else in the world (J.C. Caldwell, 1992). People have been willing to restrict fertility when they knew that it was respectable and moral to do so, that others were doing so, and that the government and the national leadership felt it the proper and necessary thing to do. The success of such leadership is, at least in retrospect, understandable in Confucian and Hindu societies, but it is more unexpected that Muslim Indonesia and Bangladesh should also have followed the same path. Bangladesh is, of course, a South Asian country, with traditions of government and elite leadership influenced by Mogul and British administration, by Hindu society and more recently by military attitudes both when forming government and when not doing so. The administrative system assumes such leadership. Legitimation is also provided by the simple fact of family planning being practised and fertility control being achieved. Doubtless, the fact that one-third of married Matlab Treatment Area women were practising family planning in the early 1980s established a base for the subsequent rise in levels.

\section{The supply and demand sides}

Because the present program - essentially the FPHSP one - succeeded where the CDP failed, and because the transition between the two was marked by the present work force coming into existence, the analysis of that success has always been dominated by the dissection of how that work force achieves its aims. The users have been treated as essentially passive: reassured rather than demanding.

Yet the study of family planning success has elsewhere credited user demand with a substantial part of the responsibility for success, in that the population makes its needs known by refusing contraception until a suitable method meeting those needs and aims is offered. Potter (1971) argued that the Taiwan data showed that the IUD did not meet the needs of a sufficient proportion of Taiwanese to achieve fertility transition without the program supplementing it with other methods to meet the circumstances and requirements of other couples. Freedman and Berelson (1976) showed that each rise to a new level of contraceptive prevalence in five major Asian programs (Taiwan, South Korea, Thailand, Hong Kong and India) was largely explained by the addition of a new method to the range being offered. Jain (1989: 10-13) showed for 72 developing countries around 1982 a 
strong correlation between the availability of contraceptives (the number of methods available and the extensiveness of their availability) and the national contraceptive prevalence rate. Segal (1991) has recently argued that the rise in levels of contraceptive use has largely been the product of technological breakthroughs in the development of satisfactory methods and the speed at which they have subsequently been made available.

Posited against this tradition has been the emphasis in most Matlab papers on the primacy of sophisticated management and service delivery: a not implausible argument given the strength of the forces mounted against contraceptive success in rural Bangladesh. Yet the Matlab Treatment Area record is as convincing as any example provided by Freedman and Berelson. The great majority of the population at first rejected the condom and pill, the latter against expectation. From the time it was first offered, half of all acceptors chose injectables, again against expectation and in spite of a lack of social analysis suggesting any demand for spacing methods. Clearly, these were not the directions in which the service providers were sophisticatedly steering their charges. The pill did not become more acceptable until the mini-pill was offered in 1984, since when its proportion of all acceptors has multiplied by two-and-a-half. The IUD (Copper T) was little chosen until home insertions were added to the range of services in 1980. The result was that, as a proportion of all acceptors, its use multiplied almost sixfold between mid-1979 and early 1984. Then a new type of Copper T, which was often wrongly inserted, was introduced with the result that its use is now down by two-thirds; indeed the change in the type of Copper $\mathrm{T}$ was on its own responsible for a failure of the program to grow at all during the following two years. After 1985 the level of acceptors has been growing steadily, a phenomenon almost entirely accounted for by a new and continuous rise in DMPA (injectable) use, clearly a phenomenon less explained by a change in FVW policies or greater reassurance about side effects than by broader social changes which made more women desirous of spacing.

Phillips et al. (1989b: 233-5) have argued that Matlab is, with regard to DMPA, a special case: 'Studies of the Matlab system strongly suggest that DMPA ... succeeds mainly because the sociology of supply lends support to family planning'. They refer not only to home delivery but to the elements of the operational design [which] ensure that the quality and intensity of family planning care create a context in which limitations of DMPA can be greatly mitigated' (pp. 231-2). They also point to much lower levels of DMPA acceptance in the two separate Extension Areas where there is less FVW assurance and paramedic backup: 'In the Extension Project Areas, DMPA never contributed more than five per centage points to the overall prevalence rate ... [although] evidence suggests that the introduction of domiciliary DMPA had a modest impact on the overall prevalence of use' (p. 238). In fact, the rise in DMPA use in these two areas following its provision at the household has continued, reaching 32 per cent of all use in one of the areas and 19 per cent in the other by 1990.

The other problem in distinguishing demand from supply, and in unravelling the various roles of the service providers, is concerned with the concept of contraceptive availability. Female seclusion in rural Bangladesh means that most women cannot go to a family planning clinic for services. Without domiciliary services in Bangladesh, contraceptives would for most women be unavailable, and offering household services in Bangladesh is the equivalent to offering clinic-based services in the same town in subSaharan Africa or in a neighbouring town among the highly mobile Sri Lankan population. 
This means that, when analysing the Matlab experience to identify the elements that pertain specifically to the Bangladesh experience in comparison with the elements which are of more universal application, it is important to separate the activities of the FVWs in bringing contraception to the door from their encouragement, liberation and reassurance activities. In fact, with DMPA, the service provision is often more than bringing the service to the door. The important point is that it is brought privately inside the house, for one of the reasons for DMPA success is that a substantial number of women chose it either without their husbands knowing about it or without that knowledge being so publicly forced upon the husbands that they had to resolve their equivocal feelings on the matter.

Phillips et al. (no date) recognize this distinction and have carried out a sophisticated statistical analysis of the interaction between family planning workers and their clientele in the new Extension Areas during 1983. They distinguish the provision of contraception which would otherwise be unavailable (labelled 'demand fulfilment' or 'crystallized demand') from the conversion of attitudes and subsequent behaviour from hostility or indifference to contraception to an acceptance of it (termed 'demand generation' or 'mobilized demand'). They found the female workers, when compared with male workers, were more likely both to crystallize and generate demand, largely because in Bangladesh society men are, at the minimum, embarrassed, and, at the maximum, compromised to be found either supplying women in a one-to-one encounter with contraception or even discussing what is ultimately sexual behaviour. The research also found that the impact of family planning workers was far greater in crystallizing existing demand than in mobilizing new demand: 15 times greater among the women, and 43 times among the men, the latter being, however, of relatively little significance in either regard (Phillips et al., n.d.: 19 and Table 4). These ratios demonstrate that the FVWs are to a very great extent mobile family planning clinics: something that is essential in Bangladesh conditions. Phillips et al. (n.d.: 19) comment that 'demand crystallization plays a more significant role than demand mobilization overall because underlying adoption rates are so much higher among intenders', but it is precisely this adoption which pushes up the contraceptive prevalence rate and reduces fertility levels. This type of analysis over fairly short intervals may well underestimate the role of the FVWs as long-term social change agents bringing into existence greater numbers of 'intenders'.

\section{What has Matlab proved?}

Matlab, and Matlab alone, has shown that, without any form of governmental duress, the poorest societies in the world, and ones with life expectancies no higher than 50 years, can achieve contraceptive prevalence rates above 50 per cent and total fertility rates below four. The importance of this demonstration for sub-Saharan Africa, those parts of Asia where fertility is not yet falling, Melanesia and elsewhere can hardly be overestimated.

But what are the essential ingredients for success? This is more debatable.

The experience of the Contraceptive Distribution Project has been taken to show that it is supportive service rather than the availability of contraceptives that is central to program success and that the service is likely to work only if provided by educated and trained women drawn from the elite. The argument is persuasive. It assumes credibility from the fact that similar systems, involving the training of educated girls drawn from the localities in which they are to work, appear to have been the mechanism whereby child mortality levels have been spectacularly driven down in such countries as Sri Lanka and Botswana (Cald well and Cald well, 1991). 
Certainly this thesis is widely believed in the ICDDR,B system, and attested in papers written by people in that system, although some of the authors were not there at the time of the CDP. Much stress is laid upon the fact that Huber and Khan (1979) concluded early from the initial experience that there had been an initial effect in reducing fertility but that this was not being sustained and that improved program performance is needed to achieve substantial demographic impact over the long term' (p. 252). This quotation underscores a problem encountered in many of the subsequent papers, as to whether the subsequent 'improved program performance' meant the range of contraception offered, the improved quality of service providers, or both. Stinson et al. (1982:146) put the final nail in the CDP coffin:

This is what happened in Matlab: prevalence rates quickly peaked in the first three months of contraceptive distribution and then declined steadily. An increasing proportion of users, moreover, switched from pills to less effective coitus-linked methods such as condoms. The resulting demographic impact was temporary and largely limited to older women ... Thus, ubiquitous availability of contraception alone does not appear to be the solution to high birth rates in Bangladesh.

This is a good summary of what has come to be the conventional wisdom.

Yet, there are problems. (1) The way that the CDP was done, with its saturation approach, almost certainly meant that there was a politeness response taking the form either of not trying the contraceptive at all or doing so only briefly in order to keep the promise to do so, and that real prevalence rates, and hence subsequent dropout rates, were never nearly as high as recorded by the surveys. (2) The switch to condoms occurred because the experiment with condom distribution began one year later, again doubtless with a politeness response. (3) The demographic impact of the CDP, and indeed its service impact, can never be finally assessed because within two years of its commencement the same population became part of a more comprehensive project, the FPHSP (actually both ran parallel for a subsequent year in the same population). It is problematic for another reason. Neither the TA nor the CA can be compared in terms of fertility for the CDP period with the previous two-year period because the earlier period was characterized by much lower fertility in each area explained by the impact of famine (fertility actually rose during the project, if we compare the total fertility rates for 1976-77 with 1974-75, by 28 per cent in the TA and 37 per cent in the CA). Stinson et al.'s conclusions are reached by the rather worrying, but perhaps inevitable, route of comparing the relative movements of the TA and the CA. Then they concede a greater fertility reduction in the TA for 1976 but note a reversal in 1977, which might be partly explained by birth deferment. If we take a perhaps fairer approach of comparing the combined project years, 1976-77, with the combined previous two years, 1974-75, we find that in the earlier two years the TA and CA had the same fertility levels while in the latter two the TA was 6 per cent lower as measured by the total fertility rate and 4 per cent lower as measured by the general fertility rate. No one will ever know whether this was temporary. (4) The relative fertility decline in the TA compared with the CA occurred in 1976 at all ages above 20, in 1977 above 35, and in 1976-77 combined, above 25 , being greater at older ages as one would anticipate from historic fertility declines and as was also the subsequent experience of FPHSP (Phillips et al., 1988: 319-321). (5) There was no ubiquitous availability of contraception, only orals and condoms, both methods which stimulated little response in either the CDP or the FPHSP. 
Because the FPHSP simultaneously offered both a much wider range of contraception and a new, supposedly improved, type of village worker, we will never know the relative importance of each of these two ingredients. The success of the CDP DMPA project in six villages suggests, however, that, while the provision of a cafeteria range of services if of great importance, either the importance of the way such services are delivered has been overestimated, or the efficiency and acceptability of ordinary, old, illiterate village women underestimated.

FPHSP has demonstrated that even in high-fertility populations, with long periods of postpartum amenorrhoea and lactation, there is a major demand for temporary contraception for spacing; and that meeting that demand might well have a significant impact on lowering fertility. It has also demonstrated that where women have little time or privacy oral contraception may not meet that demand, but that DMPA, or possibly implants, are the only methods that might succeed.

Further, the provision of acceptable contraception, backed by the legitimation of fertility control at local and national levels, can almost certainly result in fertility decline in any Asian society and possibly anywhere in the world. Much depends on whether the national leadership and each lower echelon of society are prepared to offer that legitimation.

The family planning service model developed at Matlab, modified for government service conditions in the Extension Areas, and transferred with further modifications to the National Program, is undoubtedly the right formula for Bangladesh, a credit to the work of ICDDR,B and a justification of investment in expensive experimental and demonstration projects. This does not mean that every ingredient was of equal importance, especially when transferred to very different societies. What, then, is transferable?

The Matlab experience reinforces other demonstrations that methods of contraception are not interchangeable. In poor societies, not fully convinced about the need for contraception, large segments of the society will continue to reproduce unless offered a form of contraception that meets their needs. Matlab has strongly supported the central importance of a broad range of services and the introduction of new contraceptive technologies as they are developed, even though this may not have been the clearest message of many of the papers published on the project. It suggests that greater concentration on injectables, and probably also Norplant, may be effective in such societies. Matlab's experience certainly did not discount the value of the saturation availability of even some form of contraception although there are issues about how such services are provided.

It also demonstrates that contraception must be available, which, in purdah societies like Bangladesh, means delivery of even what are usually regarded as clinic-based methods to the house, and often privately to the inside of the house, by female workers. In societies where women are not secluded the equivalent is services within an area easily and usually traversed by the women. Nevertheless, in societies where women are mobile but are sensitive about others knowing that they wish to restrict fertility - a typical sub-Saharan African situation - the equivalent to the Bangladeshi service within the home is service in a facility where neither the other services offered nor the time of attendance identifies the client to members of the community as seeking or practising family planning.

The fact that the Matlab analyses of service delivery have probably overstressed emotional support and reassurance compared with the efficient delivery of services does 
not mean that motivation and the legitimation of family planning are not important. Success in these areas is difficult to measure. There is some evidence, even in Matlab, that the expressed, and known, viewpoints of governments and elites is a major source of legitimation of both contraception and of women making decisions in this and other areas.

The most difficult question, and an important one in terms of the cost of programs, is just how necessary it is to recruit family planning workers with all the characteristics specified in the Matlab program: female, young, married, educated, resident in the locality, from elite families, and practising family planning. Some of this list, still hallowed in Matlab, was probably little more than a reaction to a previous, different program that was regarded as being unsuccessful. In purdah societies the workers probably should be female, married and locally resident, although elsewhere each of these provisions can be relaxed according to local circumstances. Even in Matlab there has never been any very convincing demonstration of the critical importance of youth, high social status or even of very much education. These characteristics all appeal to outside experts, and are compatible with a local professional team, but whether they are equally attractive to poor, illiterate, high-parity, often middle aged, rural women is by no means clear. Whether the program actually recruited women who had previously been practising family planning before they heard of the job specifications is far from certain.

Finally, the strong emphasis on the supply or managerial side of the Matlab family planning program has weakened the guidance that could have come from more useroriented research. To take the most obvious example, in a program dominated by a userdemand for DMPA, it is of vital importance to know why this is so and what the aims and circumstances of the Matlab women and couples are and how they have given rise to this phenomenon.

\section{Acknowledgements}

Betty Kavunenko and Wendy Cosford provided research assistance and Pat Goodall word processing. The authors are grateful for cooperation from ICDDR,B staff over the years, and especially for their discussion of this paper and also that of Barkat-e-Khuda during November 1991 and at a seminar during this period. For assistance and access to new papers, without committing themselves to any of the argument in the paper, they wish to thank James Phillips and Ruth Simmons.

\section{References}

Adil, E. 1966, 'Pakistan', in B. Berelson et al., eds, Family Planning and Population Programs: A Review of World Developments, University of Chicago Press, Chicago pp.123-134.

Arthur, W.B. and McNicoll, G. 1978, 'An analytical survey of population and development in Bangladesh', Population and Development Review, 4,1:23-80.

Bangladesh Bureau of Statistics, 1991, Preliminary Report: Population Census, 1991, Government of the People's Republic of Bangladesh, Dhaka.

Bhatia, S., Mosley, W.H., Faruque, A.S.G., and Chakraborty, J. 1980, 'The Matlab Family PlanningHealth Services Project', Studies in Family Planning, 11,6:202-212.

Cain, M.T. 1977, 'The economic activities of children in a village in Bangladesh', Population and Development Review, 3,3:201-227.

Cain, M.T. 1978, 'The household life cycle and economic mobility in rural Bangladesh', Population and Development Review, 4,3:421-438. 
Cain, M.T, 1981, 'Risk and insurance: perspectives on fertility and agrarian change in India and Bangladesh', Population and Development Review,7,3:435-474.

Caldwell, B.K. 1992, Patterns of marriage change in Sri Lanka, PhD thesis, Demography Program, Australian National University, Canberra.

Caldwell J.C. 1981, 'The mechanisms of demographic change in historical perspective', Population Studies, 35,1:5-27.

Caldwell, J.C. 1991, 'The soft underbelly of development: demographic transition in conditions of limited economic change', in S. Fischer, D. de Tray and S. Shah, eds, Proceedings of the World Bank Annual Conference on Development Economics 1990, World Bank, Washington, D.C., pp $207-$ 253.

Caldwell, J.C. 1992, 'The Asian fertility revolution: its implications for transition theories', in R. Leete and I. Alam, eds, The Revolution in Asian Fertility: Dimensions, Causes and Implications, Clarendon Press, Oxford, forthcoming.

Caldwell, J.C. and Caldwell, P. 1977, 'The role of marital sexual abstinence in determining fertility: a study of the Yoruba in Nigeria', Population Studies, 36,2:193-217.

Caldwell, J.C. and Caldwell, P. 1981, 'Cause and sequence in the reduction of postnatal abstinence in Ibadan City, Nigeria', in H.J. Page and R. Lesthaeghe, eds, Child-Spacing in Tropical Africa: Traditions and Change, Academic Press, London, pp.181-199.

Caldwell, J.C. and Caldwell, P. 1991, 'The roles of women, families and communities in preventing illness and providing health services in developing countries', Paper presented at National Academy of Sciences Workshop on Policy and Planning Implications of the Epidemiologic Transition, Washington, DC, November 20-22.

Caldwell, J.C. Gaminiratne, K.H.W., Caldwell, P., de Silva, S., Caldwell, B., Weeraratne, N. and Silva, P., 1987, 'The role of traditional fertility regulation in Sri Lanka', Studies in Family Planning, 18,1:14-15.

Caldwell, J.C. Jalaluddin, A.K.M., Caldwell, P. and Cosford, W. 1984. 'The changing nature of family labour in rural and urban Bangladesh: Implications for fertility transition'. Canadian Studies in Population 2, 2: 165-198.

Caldwell, J.C. Reddy, P.H. and Caldwell, P. 1982, 'The causes of demographic change in rural South India', Population and Development Review, 8,4:689-727.

Caldwell, J.C. Reddy, P.H. and Caldwell, P. 1983, 'The causes of marriage change in South India', Population Studies, 37,3:343-361.

Caldwell, J.C., P.H. Reddy and P. Caldwell. 1988. The Causes of Demographic Change: Experimental Research in South India. Madison: University of Wisconsin Press.

Caldwell, P. 1990, Matlab visit field notes.

Caldwell, P. and Caldwell, J.C. 1981, 'The function of child-spacing in traditional societies and the direction of change'. in H.J. Page and R. Lesthaeghe, eds, Child-Spacing in Tropical Africa: Traditions and Change, Academic Press, London, pp. 73-92.

Chen, L.C. Ahmed, S., Gesche, M. and Mosley, W.H. 1974, 'A prospective study of birth interval dynamics in rural Bangladesh', Population Studies, 28,2:277-297.

Cleland, J. and Mauldin, W.P. 1987, 'Study of compensation payments and family planning in Bangladesh: main findings and recommendations', Report to the World Bank and NIPORT, Dhaka.

Duza, M.B. and Nag, M. 1988, 'High contraceptive prevalence in Matlab, Bangladesh: underlying processes and implications', Paper presented at International Union for the Scientific Study of Population Seminar on Fertility Transition in Asia: Diversity and Change, Bangkok 28-31 March. 
Fauveau, V. Wojtyniak, B., Koening, M.A., Chakraborty, J. and Chowdhury, A.I. 1989, 'Epidemiology and cause of deaths among women in rural Bangladesh', International Journal of Epidemiology, 18,1:139-145.

Flandrin, J.L. 1979, Families in Former Times: Kinship, Household and Sexuality, University of Cambridge Press, Cambridge.

Ford, K. 1992, 'Correlation between subsequent lengths of postpartum amenorrhea in a prospective study of breastfeeding women in rural Bangladesh', Journal of Biosocial Science, in press.

Foster, A. 1991, Household partition in rural Bangladesh, mimeograph, Economics Department and Population Studies Center, University of Pennsylvania, Philadelphia.

Freedman, D. and Freedman, R. 1986, 'Adding demand-side variables to the interaction between demand and supply in Bangladesh', Report prepared for the Policy and Research Division, Population, Health and Nutrition Department, World Bank. Washington, D.C.

Freedman, R. and Berelson, B. 1976, 'The record of family planning programs', Studies in Family Planning, 7,1:3-40.

Government of Bangladesh, Population Control and Family Planning Division 1978, World Fertility Survey-Bangladesh Fertility Survey, 1975-1976, First Report, Ministry of Health and Population Control, Dhaka.

Huffman, S.L., Chowdhury, A.K.M.A., Chakraborty, J. and Simpson, N.K. 1980, 'Breast-feeding patterns in rural Bangladesh', American Journal of Clinical Nutrition, 33,1:144-154.

Huber, D.H. and Khan, A.R. 1979, 'Contraceptive distribution in Bangladesh villages: the initial impact', Studies in Family Planning, 10,8/9:246-253

Jain, A.K. 1989, 'Fertility reduction and the quality of family planning services', Studies in Family Planning, 20,1:1-16.

Khuda, B.-e-. 1977, 'Value of children in a Bangladesh village', in J.C. Caldwell, ed, The Persistence of High Fertility: Population Prospects in the Third World, Australian National University, Canberra, pp. 681-728.

Khuda, B.-e-. 1978, Labour utilisation in a village economy of Bangladesh, PhD thesis, Australian National University, Canberra.

Koenig, M.A., Fauveau, V., Chowdhury, A.I., Chakraborty J. and Khan, M.A. 1988, 'Maternal mortality in Matlab, Bangladesh: 1976-85', Studies in Family Planning, 19,2:69-80.

Koenig, M.A., Phillips, J.F., Campbell, O.M. and D'Souza, S. 1990, 'Birth intervals and childhood mortality in rural Bangladesh', Demography, 27,2:251-265.

Miller, J.E, Trussell, J., Pebley, A.R. and Vaughan, B. 1991, 'Birth spacing and infant health in Bangladesh and the Philippines', Paper presented to the Annual Meeting of the Population Association of America, March 21-23, Washington, D.C.

Mitra, S.N., Larson, A., Foo, G. and Islam, S. 1990, Bangladesh Contraceptive Prevalence Survey - 1989: Final Report, Mitra and Associates, Dhaka.

Mostafa, G., Wojtyniak, B., Fauveau, F. and Bhuiya, A. 1991, 'The relationship between sociodemographic variables and pregnancy loss in a rural area of Bangladesh', Journal of Biosocial Science, 23:55-63.

Muhuri, P.K. and Preston, S.H. 1991, 'Effects of family composition on mortality differentials by sex among children in Matlab, Bangladesh', Population and Development Review, 17,3:415-434.

Phillips, J.F., Hossain, M.B. and Koblinsky, M.A. 1989a, 'Improving climate of choice: the effect of organizational change on contraceptive behaviour in rural Bangladesh', in R.A. Bulatao, J.A. Palmore and S.B. Ward, eds, Choosing a Contraceptive: Factors in Method Choice in Asia and the United States, Westview Press, Boulder, pp.212-236. 
Phillips, J.F., Hossain, M.B., Huque, A.A.Z. and Akbar, J. 1989b, 'A case study of contraceptive introduction: domiciliary depo-medroxy progesterone acetate services in rural Bangladesh', in S.J. Segal, A.O. Tsui and S.M. Rogers, eds, Demographic and Programmatic Consequences of Contraceptive Innovations, Plenum, New York, pp.227-248.

Phillips, J.F., Hossain, M.B., Simmons, R. and Koenig, M. No date, Worker-client exchanges and contraceptive use in rural Bangladesh, mimeograph, ICDDR,B, Dhaka.

Phillips, J.F., Simmons, R., Koenig, M. and Chakraborty, J. 1988, 'Determinants of reproductive change in a traditional society: evidence from Matlab, Bangladesh', Studies in Family Planning, 19,6:313334.

Phillips, J.F., Stinson, W.S., Bhatia, S., Rahman, M. and Chakraborty, J. 1982, 'The demographic impact of the Family Planning - Health Services Project in Matlab, Bangladesh', Studies in Family Planning, 13,5:131-148.

Potter, R.G. 1971, 'Inadequacy of a one-method family planning program', Studies in Family Planning , 2,1:1-6.

Rahman, M. 1986, Tradition, Development and the Individual: A Study of Conflicts and Support to Family Planning in Rural Bangladesh, edited P. Kane and L. Ruzicka, Australian National University, Canberra.

Rahman, M., Mosley, W.H., Khan, A.R., Chowdhury, A.I. and Chakraborty, J. 1979, 'The Matlab Contraceptive Distribution Project', ICDDR,B Scientific Reports 32, International Centre for Diarrhoeal Disease Research, Bangladesh, Dhaka.

Rahman, M., Mosley, W.H., Khan, A.R., Chowdhury, A.I. and Chakraborty, J. 1980, 'Contraceptive distribution in Bangladesh: some lessons learned', Studies in Family Planning, 11,6:191-201.

Rahman, M., Osteria, T., Chakraborty, J., Huber, D.H. and Mosley, W.H. 1978, 'A study of the field worker performance in the Matlab Contraceptive Distribution Project', ICDDR,B Scientific Reports 32, International Centre for Diarrhoeal Disease Research, Bangladesh, Dhaka.

Rele, J.R. and Alam, I. 1988, 'Fertility transition in Asia: The statistical evidence'. Paper presented at International Union for the Scientific Study of Population Seminar on Fertility Transition in Asia, Bangkok 28-31 March.

Robinson, W.C. 1986, 'High fertility as risk-insurance', Population Studies, 40,2:289-298.

Segal, S.J. 1991, The role of technology in population policy, Population Council, New York, mimeograph.

Shah, I.H. and Cleland, J.G. 1988, 'High fertility in Bangladesh, Nepal and Pakistan: motives versus means', Paper presented at International Union for the Scientific Study of Population Seminar on Fertility Transition in Asia, Bangkok 28-31 March.

Shahidullah, M. 1991, 'Is breastfeeding a crucial determinant of child survival? Evidence for Matlab, Bangladesh', Working Papers in Demography, 30, Australian National University, Canberra.

Simmons, R. 1990, Employment in family planning and women's status: the personal transformation of community workers, mimeograph.

Simmons, R., Baqee, L., Koenig, M.A. and Phillips, J.F. 1988, 'Beyond supply: the importance of female family planning workers in rural Bangladesh', Studies in Family Planning, 19,1:29-38.

Srinivasan, K., Reddy, P.H. and Raju, K.N.M. 1978, 'From one generation to the next: changes in fertility, family size preferences and family planning in an Indian state between 1951 and 1975', Studies in Family Planning,9,10/11:258-271.

Stewart, M.K., Riley, A.P., Chakraborty, J. and Cartwright, K. 1991, 'A study of the relationship between menstrual disturbances and continuation of DMPA in rural Bangladesh', Paper presented at the Annual Meeting of the Population Association of America, Washington, D.C. 
Stinson, W.S., Phillips, J.F., Rahman, M. and Chakraborty, J. 1982, 'The demographic impact of the Contraceptive Distribution Project in Matlab, Bangladesh', Studies in Family Planning, 13,5:141148.

Tan, J.P. 1983, 'Marital fertility at older ages in Nepal, Bangladesh and Sri Lanka', Population Studies, 37,3:433-444.

Trussell, J., Grummer-Strawn, L., Rodriguez, G. and Van Landingham, M.J. 1991, 'Trends and differentials in breastfeeding behaviour: evidence from WFS and DHS', Working Paper No. 90-1, Office of Population Research, Princeton University, Princeton.

World Bank 1991, World Development Report 1991, Oxford University Press, New York. 


\section{HEALTH TRANSITION CENTRE PUBLICATIONS}

\section{WORKING PAPERS}

1. Larson, Ann (1989)

Social context of human immunodeficiency virus transmission in Africa: historical and cultural bases of east and central African sexual relations

Review of Infectious Diseases, II, 5:716-731

2 Caldwell, John C., Pat Caldwell and Pat Quiggin (1989)

The social context of AIDS in sub-Saharan Africa

Population and Development Review, 15, 2:185-234

3. Orubuloye, I.O., John C. Caldwell and Pat Caldwell (1991)

Sexual networking in the Ekiti District of Nigeria

Studies in Family Planning 22,2:61-73

4. Caldwell, John C., I.O. Orubuloye and Pat Caldwell (1991)

The destabilization of the traditional Yoruba sexual system

Population and Development Review, 17,2:229-262

5. Caldwell, John C., Pat Caldwell and I.O. Orubuloye (1990)

The family and sexual networking in sub-Saharan Africa:

historic regional differences and present day implications.

6. Caldwell, Pat (1990)

Research Priorities: Behavioural Research

(with an Annexe on needed research with

priority suggestions)

6a. Caldwell, Pat (1990)

Annexe to Research Priorities: Behavioural Research

7. Caldwell, Pat and John C. Caldwell (1990)

Gender implications for survival in South Asia

8. Orubuloye, I.O., John C. Caldwell and Pat Caldwell (1991)

The impact of family and budget structure on health treatment in Nigeria

9. Caldwell, John C., I.O. Orubuloye and Pat Caldwell (1991)

Underreaction to AIDS in Sub-Saharan Africa

10. Orubuloye, I.O., Pat Caldwell and John C. Caldwell (1992)

The role of high-risk occupations in the spread of AIDS: truckdrivers and itinerant market women in Nigeria

11. Orubuloye, I.O., John C. Caldwell and Pat Caldwell (1992)

Diffusion and focus in sexual networking: identifying partners and partners' partners 
12. Orubuloye, I.O., Pat Caldwell and John C. Caldwell (1992)

African women's control over their sexuality in an era of AIDS

13 Caldwell, John C., I.O. Orubuloye and Pat Caldwell (1992)

Africa's new kind of fertility transition

14. Caldwell, John C. and Pat Caldwell (1992)

What does the Matlab fertility experience really show?

\section{HEALTH TRANSITION SERIES}

1. Caldwell, John C. and Gigi Santow (eds) (1989).

Selected Readings in the Cultural, Social and Behavioural Determinants of Health.

Canberra: Health Transition Centre, Australian National University. xix $+305 p p$

2 Caldwell, John C., Sally Findley, Pat Cald well, Gigi Santow,

Wendy Cosford, Jennifer Braid and Daphne Broers-Freeman (eds) (1990), What we know about Health Transition: the cultural, social and behavioural determinants of health, Canberra: Health Transition Centre, Australian National University xix + 933pp.

3. Cleland, John and Allan G. Hill (eds) (1991)

The Health Transition: Methods and Measures, Canberra: Health Transition Centre, Australian National University.

\section{JOURNAL}

Health Transition Review Vol. 1 No. 1 April, 1991

Health Transition Review Vol. 1 No. 2 October, 1991 